\title{
UPAYA MENINGKATKAN HASIL BELAJAR KEMAMPUAN GERAK DASAR DENGAN MENGGUNAKAN ALAT BANTU PEMBELAJARAN SEDERHANA DI SEKOLAH DASAR
}

\author{
Andri Arif Kustiawan ${ }^{1}$, Aba Sandi Prayoga ${ }^{2}$, Arief Nur Wahyudi ${ }^{3}$ \\ STKIP Modren Ngawi ${ }^{123}$ \\ Email: andrigww3m@gmail.com ${ }^{1}$, adamhamis79@gmail.com ${ }^{2}$, \\ ariefnurwahyudi29@gmail.com ${ }^{3}$
}

\begin{abstract}
Abstrak
Tujuan penelitian ini adalah untuk meningkatkan hasil belajar kemampuan gerak dasar manipulatif menggunakan alat bantu pembelajaran sederhana pada siswa kelas II SDN Ploso I Kabupaten Pacitan tahun pelajaran 2018/2019.

Penelitian ini merupakan penelitian tindakan kelas (PTK). Penelitian ini dilaksanakan dalam dua siklus, dengan tiap siklus terdiri atas perencanaan, pelaksanaan,observasi,dan refleksi. Subjek penelitian adalah siswa kelas II SDN Ploso I Kabupaten Pacitan yang berjumlah 30 siswa yang terdiri dari 20 siswa putra dan 10 siswa putri. Sumber data berasal dari guru,peserta didik,dan peneliti. Tekhnik pengumpulan data adalah dengan observasi,penilaian dan dokumentasi. Validitas data menggunakan tekhnik triangulasi data. Analisis data menggunakan tekhnik deskriptif yang didasarkan pada analisis kualitatif dengan prosentase.

Dari hasil penelitian ini analisis yang diperoleh dari kondisi awal siswa yang lulus hanya 9 siswa atau $30 \%$, di siklus pertama siswa yang lulus menjadi 16 siswa atau 53,34\% dan di siklus kedua siswa yang lulus menjadi 26 siswa atau 86,67\% sedangkan 4 siswa lainnya belum tuntas.

Simpulan dari penelitian ini adalah dengan menggunakan alat bantu pembelajaran sederhana dapat meningkatkan hasil belajar kemampuan gerak dasar manipulatif pada siswa kelas II SDN Ploso I Kabupaten Pacitan tahun pelajaran 2018/2019.
\end{abstract}

Kata Kunci : hasil belajar kemampuan gerak dasar manipulatif, alat bantu pembelajaran sederhana

Improve learning outcomes movement using the tools of manipulative simple learning in primary schoo

\begin{abstract}
:
The purpose of this research is to improve learning outcomes capability of motion the base of manipulative manner using the tools simple learning to promote disorder to to their students the class ii of state elementary school sdn ploso i district level pacitan the new school term of 2018 / 2019

The research is research ptk ) (class action. This study was conducted in two cycles , with each cycle consists of planning, the implementation of, observation, and reflection.A subject of study were students class iii sdn ploso ii district pacitan covering 30 students consisting of 10 students 20 students son and daughter. The data derived from teachers, students, and researchers. Tekhnik data collection is by observation, assessment and
\end{abstract}


documentation. The validity of the data using tekhnik triangulation .Data analysis using tekhnik descriptive based on close analysis of prosentase qualitative

From the result of this research of analysis that was obtained of the initial conditions of students who graduate only 9 a student or $30 \%$, in the first a notebook detailing the development of students who graduated into 16 there were students or 53,34\% and all that is in second keeps a notebook detailing the students who graduated into 26 students or $86,67 \%$ while 4 other students from getting possessed have not been solved .

Drawing conclusions from the study is by using the tools learning simple can improve learning outcomes capability of motion basic manipulative to their students class ii sdn ploso i kabupaten pacitan years lessons 2018 / 2019.

Key Words: $\quad$ learning outcomes movement the manipulative , simple learning tools

\section{A. PENDAHULUAN}

Pendidikan jasmani merupakan bagian penting dari kehidupan manusia. Berolahraga dapat meningkatkan kesegaran jasmani dan kondisi fisik seseorang sehingga untuk melaksanakan aktivitas sehari-hari tanpa mengalami kelelahan yang berarti. Melalui kegiatan olahraga dapat membentuk manusia yang sehat jasmani dan memiliki watak disiplin serta sportif yang tinggi dan pada akhirnya akan membentuk manusia yang berkualitas.

Dalam Pendidikan jasmani bukan hanya merupakan bagian penting bagi kehidupan manusia saja. Pendidikan jasmani juga merupakan bagian penting dari proses pendidikan. Artinya, melalui pendidikan jasmani yang diarahkan dengan baik, anak akan mengembangkan keterampilan yang berguna bagi pengisian waktu senggang, terlibat dalam aktivitas yang kondusif untuk mengembangkan hidup sehat, berkembang secara sosial, dan menyumbang pada kesehatan fisik dan mentalnya.

Pelajaran pendidikan jasmani banyak permasalahan yang muncul pada saat berlangsungnya proses belajar mengajar yaitu seperti anak didik timbul sifat bermalasmalasan untuk melakukan aktivitas jasmani. Saat kegiatan belajar mengajar anak didik pura-pura sakit,ijin, dan tidak mengikuti pelajaran dengan berbagai macam alasan.

Pada saat melaksanakan pembelajaran pendidikan jasmani seorang guru harus aktif menciptakan suasana pembelajaran yang sebaik mungkin agar motivasi belajar siswa dapat meningkat. Tujuan pembelajaran dapat tercapai dengan baik bila seorang guru memiliki kemampuan untuk membangkitkan motivasi siswa dalam belajar. Dalam rangka mencapai tujuan tersebut, pembelajaran yang dilakukan antara guru dan siswa hendaknya mengacu pada aktivitas dan partisipasi siswa. Guru tidak hanya melakukan 


\section{Upaya Meningkatkan Hasil Belajar Kemampuan Gerak Dasar Dengan Menggunakan Alat \\ Bantu Pembelajaran Sederhana Di Sekolah Dasar \\ Oleh : Andri Arif Kustiawan ${ }^{1}$, Aba Sandi Prayoga ${ }^{2}$, Arief Nur Wahyudi ${ }^{3}$}

kegiatan penyampaian pengetahuan,keterampilan, dan sikap kepada siswa akan tetapi guru diharapkan mampu membawa siswa untuk aktif dalam berbagai bentuk pembelajaran.

Pembelajaran pendidikan jasmani di sekolah dasar diajarkan beberapa aktivitas olahraga yang berisi berbagai macam kemampuan gerak dasar yang terangkum dalam kurikulum pendidikan jasmani. Salah satunya adalah kemampuan gerak dasar manipulatif yang meliputi gerakan melempar,menangkap dan menendang.

Kemampuan gerak dasar manipulatif adalah suatu kemampuan memanipulasi objek yang bergerak. Kemampuan melempar, menangkap dan menendang menjadi salah satu kemampuan manipulatif yang sangat diperlukan pada masa perkembangan. Karena keterampilan ini dapat menopang terhadap kebutuhan gerak pada usia anak-anak. Adapun keterampilan lainya seperti menggiring, dan memukul diperlukan pada usia remaja dan dewasa.

Kemampuan manipulatif akan berkembang seiring bertambahnya usia dan akan lebih cepat lagi apabila diiringi serangkaian latihan belajar gerak. Siapapun anak yang normal pasti akan menguasai kemampuan melempar,menangkap dan menendang tanpa harus berlatih. Namun perlu dipertanyakan sampai manakah tingkat keterampilan ini bisa berkembang jika tidak pernah berlatih belajar gerak secara khusus.

Dalam kegiatan pembelajaran dengan materi melempar,menangkap,dan menendang dengan media bola yang telah diajarkan oleh guru di SDN Ploso I Pacitan pada kelas II masih terlihat biasa saja dan ketertarikan anak untuk memperbanyak gerak masih sangat kurang, hal ini dikarenakan media pembelajaran yang masih terlihat kurang bervariasi sehingga tidak dapat memotivasi anak didik untuk tertarik melakukan gerakangerakan. Hal ini diperparah dengan kondisi kelas dengan anak didik yang bercanda sesukanya sendiri saat materi sedang diberikan oleh guru pendidikan jasmani.

Dengan demikian maka hasil belajar kemampuan gerak dasar manipulatif melempar, menangkap dan menendang dengan media bola pun berbanding lurus dengan fakta yang ada di lapangan. Berdasarkan hasil observasi yang telah dilakukan di SDN Ploso I Pacitan pada siswa kelas II, hasil belajar siswa masih belum sesuai harapan dan masih banyak yang belum tuntas dari KKM atau Kriteria Ketuntasan Minimal yang telah ditetapkan. Dari 30 siswa dengan KKM 75 hanya 9 siswa atau 30\% saja yang bisa dikatakan baik dan tuntas sedangkan 21 siswa atau $70 \%$ lainnya masih belum tuntas KKM. 


\section{Upaya Meningkatkan Hasil Belajar Kemampuan Gerak Dasar Dengan Menggunakan Alat \\ Bantu Pembelajaran Sederhana Di Sekolah Dasar \\ Oleh : Andri Arif Kustiawan ${ }^{1}$, Aba Sandi Prayoga ${ }^{2}$, Arief Nur Wahyudi ${ }^{3}$}

Alat bantu pembelajaran sederhana merupakan sarana untuk membantu proses pembelajaran agar tujuan pembelajaran dapat dicapai oleh anak didik. Selain itu alat bantu pembelajaran sederhana juga dapat menghidupkan suasana pembelajaran agar tidak monoton. Pembelajaran yang monoton akan membuat anak didik kurang tertarik mengikuti dan melakukan materi pembelajaran yang diajarkan.

Untuk menciptakan suatu alat bantu pembelajaran yang sederhana tidak perlu mengeluarkan biaya yang banyak. Banyak sekali barang-barang yang sudah tidak terpakai yang bisa dimanfaatkan untuk dijadikan alat bantu pembelajaran sederhana. Dengan memperbanyak referensi dan kreatifitas maka dengan barang yang simple dan tidak terpakai atau bahkan barang yang harusnya dibuang justru dapat dijadikan alat untuk membantu proses pembelajaran di sekolah.

Untuk mengetahui seberapa maksimal penerapan alat bantu pembelajaran sederhana ini dapat meningkatkan hasil belajar kemampuan gerak dasar manipulatif melempar, menangkap, dan menendang, maka peneliti tertarik melakukan PTK pada siswa kelas II SDN Ploso I Kabupaten Pacitan tahun pelajaran 2018/2019 dengan judul “Upaya Meningkatkan Hasil Belajar Kemampuan Gerak Dasar Menggunakan Alat Bantu Pembelajaran Sederhana Pada siswa kelas II SDN Ploso I Kabupaten Pacitan Tahun Pelajaran 2018/2019”.

\section{B. METODE PENELITIAN}

Penelitian merupakan penilitian tindakan kelas (PTK). Peneliti berkolaborasi dengan guru untuk menyelesaikan permasalahan proses pembelajaran dikelas. Peneliti mengajukan solusi untuk memecahkan proses pembelajaran dikelas berdasarkan observasi yang dilakukan peneliti.

Solusi yang dimaksud adalah tindakan berupa penerapan alat bantu pembelajaran sederhana untukmeningkatkan hasil belajar kemampuan gerak dasar manipulatif pada siswa kelas II SDN Ploso I Kabupaten Pacitan. Penerapan alat bantu pembelajaran sederhana dilakukan secara berulang dalam setiap pembelajaranya, artinya cara menerapkan alat bantu pembelajaran sederhana dalam setiap siklusnya adalah sama baik pada siklus I maupun pada siklus II. Perbedaan terletak pada refleksi dari setiap siklus, sebab refleksi ini tergantung pada fakta dan interprestasi data yang diperoleh atau kondisi yang ada dilapangan. Refleksi dilakukan untuk memperoleh hasil yang maksimal mengenai alat bantu pembelajaran 


\section{Upaya Meningkatkan Hasil Belajar Kemampuan Gerak Dasar Dengan Menggunakan Alat Bantu Pembelajaran Sederhana Di Sekolah Dasar \\ Oleh : Andri Arif Kustiawan ${ }^{1}$, Aba Sandi Prayoga ${ }^{2}$, Arief Nur Wahyudi ${ }^{3}$}

sederhana untuk meningkatkan hasil belajar kemampuan gerak dasar manipulatif pada siswa kelas II SDN Ploso I Kabupaten Pacitan.

Analisis data yang digunakan dalam penelitian ini analisis diskriptif dengan prosentase. Pengumpulan data menggunakan tes dan observasi dimana tes digunakan untuk mengumpulkan data dan mengukurkemampuan siswa dalam aspek kognitif atau tingkat penguasaan materi pembelajaran kemampuan gerak dasar manipulatif dalam bentuk lisan dan tertulis sedangkan observasi digunakan sebagai teknik pengumpulan data tentang hasil belajar kemampuan gerak dasar manipulatif siswa dan tentang aktifitas siswa selama mengikuti proses belajar mengajar. Uji validitasi data merupakan suatu cara untuk menentukan suatu keabsahan data yang diperoleh.dalam hal ini, untuk meningkatkan validitas data yang diperoleh, peneliti menggunakan triangulasi data dimana data yang sama akan lebih mantap kebenaranya apabila diperoleh dari beberapa sumber data yang berbeda.

\section{HASIL PENELITIAN}

Hasil penelitian ini menunjukan bahwa dengan menggunakan alat bantu pembelajaran sederhana dapat meningkatkan hasil belajarkemampuan gerak dasar manipulatif. Hasil belajar tersebut meliputi aspek pisikomotorik, kognitif, dan afektif dari 30 siswa hanya 9 siswa yang mencapai KKM atau 30\% pada kondisi awal, mengalami peningkatan menjadi 53,34\% atau 16 siswa yang mencapai batas tuntas pada siklus I. Selanjutnya meningkat menjadi $86,67 \%$ atau 26 siswa yang mencapai batas tuntas pada akhir siklus II. Hasil belajar siswa pada siklus I dan II disajikan dalam diagram berikut.

Tabel 4.3 Deskripsi Data Hasil Belajar Gerak Dasar Manipulatif Siklus 1 pertemuan 2 Pada siswa kelas II SDN Ploso I Kabupaten Pacitan Tahun Pelajaran 2018/2019

\begin{tabular}{|c|c|c|c|c|}
\hline $\begin{array}{c}\text { Rentang } \\
\text { Nilai }\end{array}$ & Kriteria & Keterangan & $\begin{array}{c}\text { Jumlah } \\
\text { Anak }\end{array}$ & Prosentase \\
\hline$>87$ & $\begin{array}{c}\text { Baik } \\
\text { Sekali }\end{array}$ & Tuntas & 0 & $0 \%$ \\
\hline $81-86$ & Baik & Tuntas & 2 & $6,67 \%$ \\
\hline $75-80$ & Cukup & Tuntas & 14 & $46,67 \%$ \\
\hline $69-74$ & Kurang & Belum & 13 & $43,33 \%$ \\
& Tuntas & & \\
\hline$<68$ & Kurang & Belum & 1 & $3,33 \%$ \\
& Sekali & Tuntas & & \\
\hline \multicolumn{5}{|c|}{ Jumlah } \\
\hline
\end{tabular}


Berdasarkan tabel 4.3 menunjukan bahwa rata-rata hasil belajar siswa yang tuntas diperoleh pada akhir tindakan siklus I sebanyak 53,34\%. Hasil ini belum menunjukan hasil yang maksimal, masih banyak nilai siswa yang dibawah KKM dan belum sesuai dengan target yang ditetapkan yaitu ketuntasan hasil belajar sebesar $80 \%$, sehingga dilanjutkan ke siklus II. Hal ini karena adanya beberapa kendala seperti, para siswa masih perlu adaptasi dengan pembelajaran menggunakan alat bantu pembelajaran sederhana, suasana kelas atau kelompok masih gaduh karena siswa sulit untuk di atur dan masih lemahnya pemahaman konsep gerak beberapa siswa terhadap materikemampuan gerak dasar manipulatif.

Berdasarkan hasil pengamatan peneliti dan guru dan hasil belajar siswa yang diperoleh pada siklus kedua ini guru dapat mengerti kekurangan-kekurangan yang telah dialami selama kegiatan belajar mengajar berlangsung. Penggunaan alat bantu pembelajaran sederhana untuk meningkatkan hasil belajar kemampuan gerak dasar manipulatif diperoleh secara maksimal.

Peneliti juga telah berhasil membangkitkan semangat siswa untuk mengikuti kegiatan belajar mengajar dengan tertib. Siswa juga tidak cepat bosan dan semakin termotivasi dengan materi pembelajaran yang diberikan, siswa telah mampu melakukan gerakan dengan baik, walaupun masih ada beberapa siswa yang kurang baik.

Tabel 4.5 Deskripsi Hasil Belajar Gerak Dasar Manipulatif Siklus 2 pertemuan 2 Pada siswa kelas II SDN Ploso I Kabupaten Pacitan Tahun Pelajaran 2017/2018

\begin{tabular}{|c|c|c|c|c|}
\hline $\begin{array}{c}\text { Rentang } \\
\text { Nilai }\end{array}$ & Kriteria & Keterangan & $\begin{array}{c}\text { Jumlah } \\
\text { Anak }\end{array}$ & Prosentase \\
\hline$>87$ & $\begin{array}{c}\text { Baik } \\
\text { Sekali }\end{array}$ & Tuntas & 3 & $10 \%$ \\
\hline $81-86$ & Baik & Tuntas & 7 & $23,33 \%$ \\
\hline $75-80$ & Cukup & Tuntas & 16 & $53,34 \%$ \\
\hline $69-74$ & Kurang & Belum & 4 & $13,33 \%$ \\
& Tuntas & & $0 \%$ \\
\hline$<68$ & Kurang & Belum & 0 & $100 \%$ \\
& Sekali & Tuntas & & 0 \\
\hline & Jumlah & & 30 & \\
\hline
\end{tabular}

Dari diskripsi data terlihat bahwa hasil belajar siswa sudah cukup baik dengan ketuntasan hasil belajar mencapai $86,67 \%$, ini berarti proses belajar mengajar telah dikatakan 


\section{Upaya Meningkatkan Hasil Belajar Kemampuan Gerak Dasar Dengan Menggunakan Alat Bantu Pembelajaran Sederhana Di Sekolah Dasar \\ Oleh : Andri Arif Kustiawan ${ }^{1}$, Aba Sandi Prayoga ${ }^{2}$, Arief Nur Wahyudi ${ }^{3}$}

berhasil karena telah melebihi indikator ketuntasan hasil belajar dari 80\%, meskipun masih terdapat 4 orang $(13,33 \%)$ siswa yang belum tuntas, hal ini disebabkan karena ada beberapa orang diantara siswa masih merasa kurang percaya diri dalam mengikuti pembelajaran sehingga tidak maksimal dalam memperoleh hasil belajarnya dan artinya keaktifan dan kemampuan siswa meningkat sesuai yang diharapkan dan pembelajaran dinyatakan berhasil meningkatkan hasil belajar siswa. Dengan alat bantu pembelajaran sederhana yang di gunakan oleh peneliti dan guru mampu mengubah kondisi kelas menjadi lebih baik, sehingga proses belajar mengajar dan pemberian materi bisa berlangsung lebih maksimal, melihat hasil yang diperoleh pada tindakan II maka Penelitian Tindakan Kelas telah memenuhi target dari rencana terget yang telah ditentukan. Dan dirasa sudah optimal sesuai dengan yang diharapkan.

\section{SIMPULAN DAN SARAN}

Simpulan

Penelitian tindakan kelas yang dilakukan pada siswa kelas II SDN Ploso I Kabupaten Pacitan tahun pelajaran 2018/2019 ini dilakukan dalam dua siklus dan berjalan dengan lancar. Dalam setiap siklus terdiri dari 4 tahapan, yaitu : (1) perencanaan tindakan, (2) pelaksanaan tindakan, (3) observasi tindakan, (4) refleksi. Pada kondisi awal siswa yang tuntas sebanyak 9 siswa atau $30 \%$. Pada siklus 1 siswa yang tuntas sebanyak 16 siswa atau 53,34 \% dan pada siklus 2 siswa yang tuntas menjadi 26 siswa atau 86,67\%. Berdasarkan analisis data yang telah dilakukan dan pembahasan yang telah dipaparkan dalam BAB IV diperoleh simpulan sebagai berikut :

Bahwa dengan menggunakan alat bantu pembelajaran sederhana dapat meningkatkan hasil belajar kemampuan gerak dasar manipulatif pada siswa kelas II SDN Ploso I Kabupaten Pacitan tahun pelajaran 2018/2019. Hal ini dibuktikan dengan analisis data yang telah dilakukan bahwa terdapat peningkatan yang signifikan pada tiap siklus dan di setiap pertemuan di tiap siklus.

Saran

Berdasarkan penelitian tindakan kelas ini, maka dapat disarankan beberapa hal yaitu sebagai berikut : 
Upaya Meningkatkan Hasil Belajar Kemampuan Gerak Dasar Dengan Menggunakan Alat

Bantu Pembelajaran Sederhana Di Sekolah Dasar

Oleh : Andri Arif Kustiawan ${ }^{1}$, Aba Sandi Prayoga ${ }^{2}$, Arief Nur Wahyudi ${ }^{3}$

1. Guru hendaknya mampu mengembangkan media alat bantu pembelajaran yang digunakan dalam pembelajaran PJOK di sekolah khususnya pembelajaran gerak dasar manipulatif dalam hal ini dibatasi pada gerak melempar,menangkap,dan menendang agar dapat meningkatkan hasil belajar dan kemampuan siswa pada mata pelajaran PJOK.

2. Guru hendaknya mampu memanfaatkan sara dan prasarana yang tersedia di sekolah untuk proses pembelajaran

3. Dengan menggunakan alat bantu pembelajaran sederhana terbukti dapat meningkatkan hasil belajar siswa dalam kemampuan gerak dasar manipulatif melempar,menangkap,dan menendang, sehingga guru hendaknya mencoba menggunakan alat bantu pembelajaran yang dirancang untuk meningkatkan hasil belajar siswa dalam materi pembelajaran olahraga yang lainnya.

\section{DAFTAR PUSTAKA}

Jufri A. Wahab, 2013. Belajar dan Pembelajaran. Bandung: Pustaka Reka Cipta.

Kern, Richard (2000). Literacy \& Language Teaching. Oxford : Oxford University Press.

M. Furqon Hidayatullah. (2008). Mendidik Anak dengan Bermain. Buku Pegangan Guru Pendidikan Jasmani di Sekolah Dasar. Universitas Sebelas Maret Surakarta

Mulyono Biyakto Atmojo. 2008. Tes dan Pengukuran pendidikan Jasmani Olahraga. Surakarta: UNS Press.

Suharsimi Arikunto. 2006, Prosedur Penelitian, Suatu Pendekatan Praktis. Jakarta: Rineka Cipta. Sugiyono, 2015. Metode Penelitian Pendidikan, Bandung, Alfabeta.

Biodata Penulis :

$\begin{array}{ll}\text { Nama } & : \text { Andri Arif Kustiawan } \\ \text { Kantor } & \text { : Aba Sandi Prayoga } \\ \text { K } & \text { Arief Nur Wodren Ngawi }\end{array}$ 